\title{
Left ventricular false tendons
}

\author{
S. Velthuis - P. J. Senden
}

Accepted: 1 June 2021 / Published online: 7 July 2021

(c) The Author(s) 2021

\begin{abstract}
Left ventricular false tendons (LVFTs) are fibromuscular structures, connecting the left ventricular free wall or papillary muscle and the ventricular septum.

There is some discussion about safety issues during intense exercise in athletes with LVFTs, as these bands have been associated with ventricular arrhythmias and abnormal cardiac remodelling. However, presence of LVFTs appears to be much more common than previously noted as imaging techniques have improved and the association between LVFTs and abnormal remodelling could very well be explained by better visibility in a dilated left ventricular lumen.

Although LVFTs may result in electrocardiographic abnormalities and could form a substrate for ventricular arrhythmias, it should be considered as a normal anatomic variant. Persons with LVFTs do not appear to have increased risk for ventricular arrhythmias or sudden cardiac death.
\end{abstract}

Keywords Left ventricular false tendon - Ventricular arrhythmias · Abnormal cardiac remodelling

\section{Case}

An 18-year-old elite soccer player was seen at our outpatient department for routine sports cardiovascular screening. He had no cardiac symptoms, palpitations, near collapse or family history of sudden death. With physical examination no abnormalities were present. His electrocardiogram revealed a fragmented QRS complex in leads III and V1 (Fig. 1). QRS width was

S. Velthuis $(\bowtie) \cdot$ P. J. Senden

Department of Cardiology, Meander Medical Centre,

Amersfoort, The Netherlands

s.velthuis@meandermc.nl
100 msec. Cardiopulmonary stress testing revealed no abnormalities, specifically no premature ventricular contractions or rhythm disorder. A prominent left ventricular false tendon from the septal base to the apex was present at the echocardiogram (Fig. 2). Additional cardiac magnetic resonance imaging (MRI) excluded other structural abnormalities, such as noncompaction cardiomyopathy, and showed no late gadolinium enhancement. Since there is some discussion about safety issues during intense exercise in elite athletes with false tendons, we reviewed the literature and performed a systematic search of peerreviewed studies that examined the clinical significance of left ventricular false tendons. Literature was searched using the PubMed database up to December 2020 using the keywords false tendon or false chordae tendineae. Each reference list was screened additionally.

\section{Introduction}

Left ventricular false tendons (LVFTs) are echogenic fibromuscular structures, connecting the left ventricular free wall or papillary muscle and the ventricular septum. As they are not related to the mitral valve apparatus, the term "false" tendon is in use. They should be differentiated from other entities such as thickened ventricular trabeculations or ventricular masses (Tab. 1). Especially diagnosis of left ventricular noncompaction can be challenging and LVFTs should not be mistaken for atypical variants of this form of cardiomyopathy $[1,2]$.

Based on their location in the apical-, mid-, or basal-third segment along the long axis of the left ventricle, LVFTs can be classified as transverse (localised to one zone), diagonal (across two zones) or longitudinal (across all three zones). Most LVFTs are transverse and located in the apex [3], although LVFTs connect- 


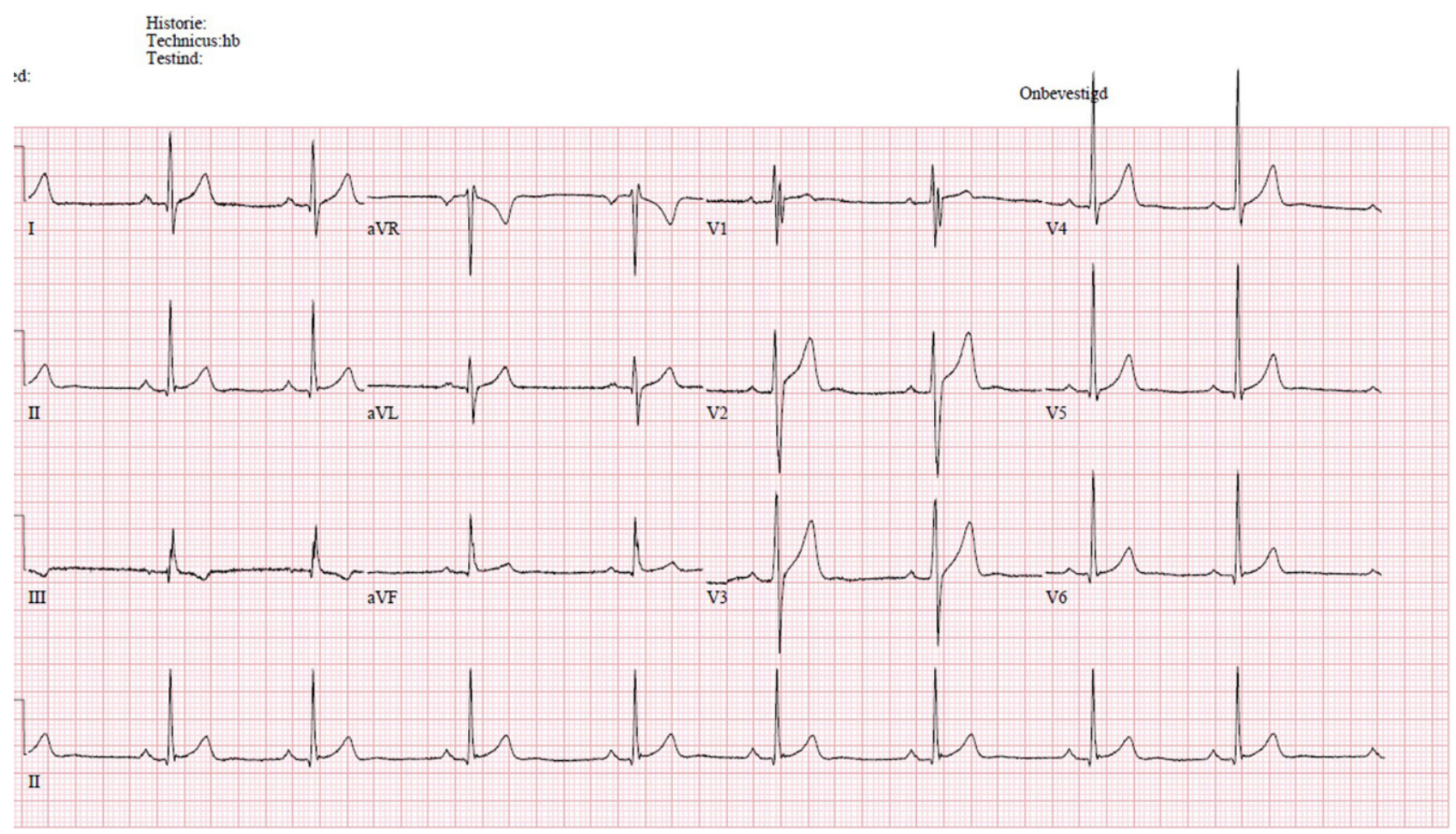

Fig. 1 Electrocardiogram with fragmented QRS complex in leads III and V1

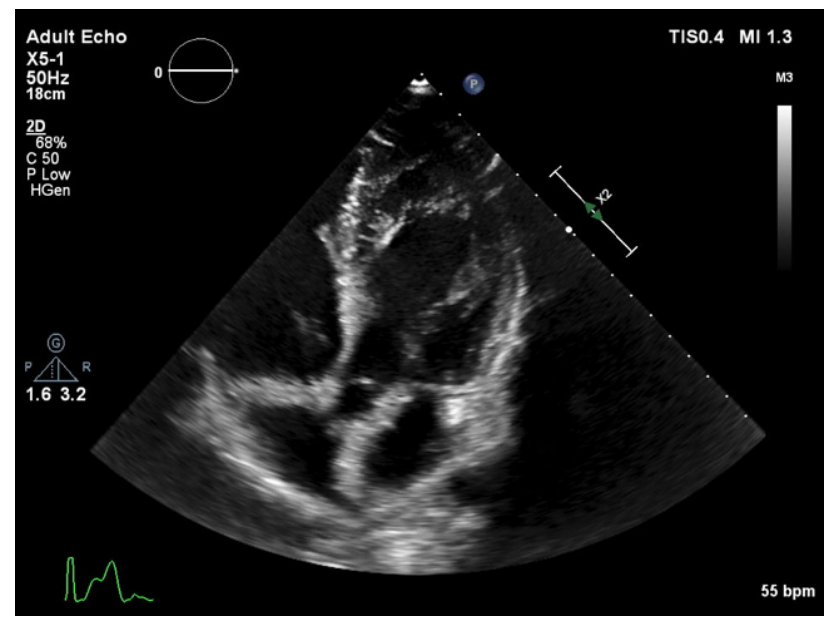

Fig. 2 Transthoracic echocardiogram. Apical 5-chamber view demonstrating prominent left ventricular false tendon from the septal base to the apex

ing the basal ventricular septum to the apical segment of the lateral free wall are also a frequent finding [4]. LVFTs can be simple, with a cord traversing the left ventricle with 1-2 points of insertion, or complex with 3 or more insertion points (branching).

\section{Prevalence of LVFTs}

The exact prevalence of LVFTs in the general population is unclear. Different studies report a widely varying prevalence between $0.4 \%$ to $83 \%[4,5]$. The detection rate can be low, as LVFTs may be ignored by echocardiographers or require additional planes to be detected. However, increased level of attention for LVFTs and the development of echocardiographic technologies and cardiac MRI have increased the detection rate of LVFTs. The only available community-based, prospective study is performed by Kenchaiah et al. and part of the well-known Framingham Heart Study [3]. This analysis between 1987 and 1990 demonstrated presence of an LVFT in 101 of 3931 (2.6\%) eligible persons screened. However, given the progress in imaging techniques during the recent years, this low percentage is surely an underestimate of the real prevalence of LVFTs. In fact, LVFTs were also found in 32 out of 176 (18\%) age and sex matched persons, where an LVFT was unidentified during initial screening of this cohort. This phenomenon is also seen in a study by Hall et al., where 15 out of 100 matched "controls" appeared to have an LVFT, supporting a more frequent prevalence of LVFTs in the general population [6]. An autopsy study by Luetmer et al. described presence of LVFTs in 55\% of hearts [7] and LVFTs were present in $78 \%$ and $83 \%$ of hospital-referred children and healthy subjects respectively [4]. The reported prevalence of LVFTs can also be subject to selection bias, as presence of LVFTs have been associated with innocent precordial murmurs. Furthermore, it is possible that LVFTs are more commonly found in young non-obese persons and in patients with dilated left ventricles, since these factors increase their visibility on echocardiography. 


\begin{tabular}{ll}
$\begin{array}{ll}\text { Table 1 } & \text { Differential diagnosis } \\
\text { Diagnosis } & \text { Description }\end{array}$ \\
$\begin{array}{l}\text { False tendons } \\
\text { Trabeculation }\end{array}$ & $\begin{array}{l}\text { Stringlike structures with free intracavitary course and con- } \\
\text { nected to ventricular walls and/or papillary muscles. Fibrous, } \\
\text { muscular or fibro-muscular composition }\end{array}$ \\
$\begin{array}{l}\text { Localised protrusions of the ventricular wall that have no free } \\
\text { intracavitary course }\end{array}$ \\
$\begin{array}{l}\text { Hypertrabe- } \\
\text { culation }\end{array}$ & $>3$ trabeculations associated with intraventricular recesses \\
\hline $\begin{array}{l}\text { Non-com- } \\
\text { paction car- } \\
\text { diomyopathy }\end{array}$ & $\begin{array}{l}\text { Congenital primary cardiomyopathy characterised by } \\
\text { sponge-like appearance of left ventricular myocardium }\end{array}$ \\
\hline $\begin{array}{l}\text { Intra-cardiac } \\
\text { thrombus or } \\
\text { tumour }\end{array}$ & $\begin{array}{l}\text { Intra-cardiac thrombi or tumours are seen in a variety of } \\
\text { clinical settings and can result in severe morbidity from } \\
\text { embolic events }\end{array}$ \\
\hline
\end{tabular}

\section{Clinical significance of LVFTs}

Although LVFTs are generally considered as benign anatomic variants, they have been associated with ventricular arrhythmias [8] and abnormal cardiac remodelling, including systolic and diastolic dysfunction and dilatation [6].

\section{LVFTs and cardiac remodelling}

Hall et al. retrospectively evaluated echocardiographic and clinical parameters of 126 patients with identified LVFTs and compared them with 85 age-matched controls without LVFTs [6]. In this study, patients with LVFTs had more prevalent heart failure, more left ventricular dilatation, were more likely to have moderate to severe mitral regurgitation and had more severe systolic and diastolic dysfunction. An LVFT location near the middle and basal left ventricular segments was associated with increased left ventricular dysfunction and dilatation, while this relation was not significant for apical LVFTs. This study suggests that LVFTs may be associated with adverse structural and functional left ventricular changes, although the mechanism by which LVFTs may cause reduced systolic and diastolic function and increased dilatation is unclear. Because the study by Hall et al. was performed in a tertiary referral centre with a cross-sectional design, a clear cause-effect relationship cannot be determined and the pathophysiologic mechanism is unknown. There has also been a selection bias in this study, as heart failure was present in up to $21 \%$ of control patients without LVFTs. The association between LVFTs and left ventricular dilatation could very well be explained by better visibility in a dilated left ventricular lumen.

Interestingly, a similar structure in the right ventricle is named the moderator band, as it was thought that its attachment instead prevents overdistension of this ventricle [9] and it has been suggested that LVFTs may retard cardiac remodelling by tethering the left ventricular wall to which they are attached. Furthermore, LVFTs that run between the papillary muscles may stabilise these structures and retard the occurrence of functional mitral valve regurgitation.

\section{LVFTs and ECG}

Presence of LVFTs may be associated with abnormal ventricular repolarisation in young healthy subjects in competitive sports $[4,10-12]$. Inverted symmetrical, sometimes biphasic, $\mathrm{T}$ waves can be seen (especially in V1-V3) which regress with increase in heart rate during exercise testing. Furthermore, the presence of LVFTs has been related to the presence of J waves, socalled terminal QRS notching or slurring [10].

\section{LVFTs and ventricular arrhythmias}

Small case series suggest an increased risk of ventricular tachycardia [8, 13-15] and speculate that conduction through LVFTs containing Purkinje fibres constitute part of the tachycardia network or that an LVFT may produce stretch in the interventricular septum with increased automaticity. Ventricular premature beats and/or arrhythmias might then be triggered due to increased automaticity of these conducting cells during mechanical stretch of the left ventricular wall at the insertion point. Thakur et al. describe a case series of 15 patients referred for catheter ablation of idiopathic left ventricular tachycardia (ILVT) [8]. This type of tachycardia is characterised by QRS complexes with a right bundle branch block morphology and left axis deviation and can be seen in patients without structural heart disease. It is often precipitated during exercise and usually responds to intravenous verapamil. In this study by Thakur et al., LVFT was found in all patients referred for ILVT ablation, while LVFT was found in 5\% of the control group. Radiofrequency catheter ablation of the postero-apical septum resulted in cure in 14 of 15 patients. This suggests that the LVFT may be responsible for this type of tachycardia. The mechanism by which the LVFT precipitates this tachycardia remains speculative. One possible explanation might be that conduction through the LVFT constitutes part of the ventricular tachycardia circuit. Or maybe the tendon produces stretch in the Purkinje fibre network in the interventricular septum. Just as the papillary muscles and right ventricular moderator band, conduction tissue in LVFTs can be the source of ventricular arrhythmias [9].

\section{LVFTs and mortality}

In the only prospective community-based Framingham study with a mean follow-up of 7.7 years, 15 of 101 (15\%) individuals with LVFTs and 19 of 151 (13\%) participants without LVFTs died. In multivariable models, presence of LVFTs was not associated with the risk of mortality [3]. 


\section{Conclusion}

LVFTs are a frequent finding in the general population, especially in young, non-obese persons. Just like other bands in the heart, LVFTs seem to be a normal anatomical structure. LVFTs may participate in electrocardiographic conduction and can theoretically be the source of ventricular arrhythmias. At this moment, there is no solid evidence relating LVFTs to excess cardiac morbidity and mortality and it would not be appropriate to classify persons with LVFTs as persons who have an increased risk of ventricular arrhythmias or sudden cardiac death.

Funding None declared

Conflict of interest S. Velthuis and P.J. Senden declare that they have no competing interests.

Open Access This article is licensed under a Creative Commons Attribution 4.0 International License, which permits use, sharing, adaptation, distribution and reproduction in any medium or format, as long as you give appropriate credit to the original author(s) and the source, provide a link to the Creative Commons licence, and indicate if changes were made. The images or other third party material in this article are included in the article's Creative Commons licence, unless indicated otherwise in a credit line to the material. If material is not included in the article's Creative Commons licence and your intended use is not permitted by statutory regulation or exceeds the permitted use, you will need to obtain permission directly from the copyright holder. To view a copy of this licence, visit http://creativecommons.org/licenses/by/4.0/.

\section{References}

1. Wegner FK, Diller GP, Eckardt L, et al. A case of "tiger heart": a distinct variant of left ventricular non-compaction. Eur Heart J Cardiovasc Imaging. 2020;21:1434.

2. Parameswaran AC, Cheong BY. Tiger heart: a variant of isolated left ventricular noncompaction? Tex Heart Inst J. 2012;39:444-5.

3. Kenchaiah S, Benjamin EJ, Evans JC, et al. Epidemiology of left ventricular false tendons: clinical correlates in the Framingham Heart Study. J Am Soc Echocardiogr. 2009;22:739-45.

4. Liu Y, Mi N, Zhou Y, et al. Transverse false tendons in the left ventricular cavity are associated with early repolarization. PLoSONE. 2015;10:e125173.

5. Philip S, Cherian KM, Wu MH, Lue HC. Left ventricular false tendons: echocardiographic, morphologic, and histopathologic studies and review of the literature. Pediatr Neonatol. 2011;52:279-86.

6. Hall ME, Halinski JA, Skelton TN, et al. Left ventricular false tendons are associated with left ventricular dilation and impaired systolic and diastolic function. Am J Med Sci. 2017;354:278-84.

7. Luetmer PH, Edwards WD, Seward JB, Tajik AJ. Incidence and distribution ofleft ventricularfalse tendons: an autopsy study of 483 normal human hearts. J Am Coll Cardiol. 1986;8:179-83.

8. Thakur RK, Klein GJ, Sivaram CA, et al. Anatomic substrate for idiopathic left ventricular tachycardia. Circulation. 1996;93:497-501.

9. Rajiah P, MacNamara J, Chaturvedi A, et al. Bands in the heart: multimodality imaging review. Radiographics. 2019;39:1238-63.

10. Nakagawa M, Ezaki K, Miyazaki H, et al. Electrocardiographic characteristics of patients with false tendon: possible association of false tendon with $\mathrm{J}$ waves. Heart Rhythm. 2012;9:782-8.

11. Gwinnutt MT. Left ventricular muscular false tendon. Resuscitation. 2008;78:3-4.

12. Lazarevic Z, Ciminelli E, Quaranta F, et al. Left ventricular false tendons and electrocardiogram repolarization abnormalities in healthy young subjects. World J Cardiol. 2016;8:590-5.

13. Wang Q, Madhavan M, Viqar-Syed M, Asirvatham SJ. Successful ablation of a narrow complex tachycardia arising from a left ventricular false tendon: mapping and optimizing energy delivery. Heart Rhythm. 2014;11:321-4.

14. Saggu DK, Shah M, Shelke A, Narasimhan C. Multiple monomorphic ventricular tachycardias in a structurally normal heart: a case report. Heart Rhythm Case Rep. 2015;1:114-6.

15. Yang YB, Li XF, Guo TT, et al. Catheter ablation of premature ventricular complexes associated with false tendons: a case report. World J Clin Cases. 2020;8:325-30. 